\title{
Methods for single-cell recording and labeling in vivo
}

\author{
Elena Cid, Liset M. de la Prida* \\ Instituto Cajal, CSIC, Ave Doctor Arce 37, Madrid, 28002, Spain
}

\section{A R T I C L E I N F O}

\section{Keywords:}

Juxtacellular

Sharp intracellular

Loose-patch

Cell-types

\begin{abstract}
A B S T R A C T
Targeting individual neurons in vivo is a key method to study the role of single cell types within local and brainwide microcircuits. While novel technological developments now permit assessing activity from large number of cells simultaneously, there is currently no better solution than glass micropipettes to relate the physiology and morphology of single-cells. Sharp intracellular, juxtacellular, loose-patch and whole-cell approaches are some of the configurations used to record and label individual neurons. Here, we review procedures to establish successful electrophysiological recordings in vivo followed by appropriate labeling for post hoc morphological analysis. We provide operational recommendations for optimizing each configuration and a generic framework for functional, neurochemical and morphological identification of the different cell-types in a given region. Finally, we highlight emerging approaches that are challenging our current paradigms for single-cell recording and labeling in the living brain.
\end{abstract}

\section{Introduction}

Assessing the structure and function of individual brain cells is a tour de force. One of the most successful solutions, i.e. the intracellular micropipette, is now 70 years old (Ling and Gerard, 1949) but earlier attempts paved the way (reviewed in Bretag, 1983). While glass capillary technologies have not evolved much over the last decades, their use for cell-type phenotyping is now revitalized by the surge of singlecell "omics" (Cembrowski, 2019).

One of the earliest successful attempts to relate the physiology and anatomy of single-cells dates back to 1974 when Kelly and Van Essen use sharp micropipettes filled with Procion yellow to record and label neurons and glial cells from the cat visual cortex in vivo (Kelly and Van Essen, 1974). The technique expanded quickly once horseradish peroxidase (HRP) was introduced to improve morphological reconstruction (Friedlander et al., 1979; Kitai et al., 1976; Lin et al., 1979; Martin and Whitteridge, 1984; Somogyi, 1988; Somogyi et al., 1983). Using intracellular approaches imposes hard demands for stability in vivo. A breakthrough was achieved in 1994, when Pinault managed to record and label extracellularly from single thalamic neurons in anesthetized rats. The new approach was further refined in a now classical paper that gave birth to the juxtacellular method (Pinault, 1996).

Intracellular and juxtacellular approaches were quickly exploited to identify single-cells from different brain regions in the anesthetized or curarized preparations (Anderson et al., 1993; Borhegyi et al., 2004; Contreras and Steriade, 1995; Kamondi et al., 1998; Klausberger et al., 2003; Li et al., 1994, 1992; Núñez et al., 1987; Sik et al., 1995; Uhlrich et al., 1991; Ylinen et al., 1995). A next step forward was moving to drug-free conditions by applying the technique to awake head-fixed animals (de Kock and Sakmann, 2009; Fee, 2000; Houweling and Brecht, 2008; Steriade et al., 2001), followed by new methods to gain stability in freely moving conditions (Burgalossi et al., 2011; Herfst et al., 2012; Lapray et al., 2012; Long et al., 2010; Long and Lee, 2012). Next, patch approaches where adapted for in vivo applications either as

\footnotetext{
* Corresponding author.

E-mail address: lmprida@cajal.csic.es (L.M. de la Prida).
} 
whole-cell recordings (Brecht and Sakmann, 2002; Crochet and Petersen, 2006; Epsztein et al., 2011; Harvey et al., 2009; Kitamura et al., 2008; Lee et al., 2009; Maier et al., 2011; Margrie et al., 2002; Oberlaender et al., 2012; Poulet and Petersen, 2008; Rancz et al., 2011) or as modified juxtacellular approaches (Burgalossi et al., 2011; de Kock and Sakmann, 2009; Herfst et al., 2012; Houweling et al., 2010; Houweling and Brecht, 2008; Oberlaender et al., 2012). A loose-patch configuration was introduced as a hybrid approach between juxtacellular and cell-attached techniques (Joshi and Hawken, 2006). This method was further combined with two-photon microscopy for targeting visualized cells, usually by shadow imaging, and has been mainly exploited for single-cell electroporation of DNA plasmids (Cohen et al., 2013; Judkewitz et al., 2009; Kitamura et al., 2008; Marshel et al., 2010; Nevian and Helmchen, 2007). Using these approaches, time-lapse recordings from exactly the same neuron can be achieved (Cohen et al., 2013) and pre-synaptic networks of single-cells are identified with genetically-engineered retrogradely-spreading rabies virus (Marshel et al., 2010; Rancz et al., 2011; Schwarz and Remy, 2019).

While new technological developments are on the way (see Section 6), the basic methodologies for recording and labeling single-cells in vivo remains unaltered. They differ slightly depending on the preparation used, recording configuration and tactics for labeling, but glass micropipettes are still the tool of excellence. After years of advances in high-throughput electrophysiological approaches, no other method has been able to provide such a detailed description of individual brain cells in vivo. Recording and labeling single-cells thus remains a classical game of skill.

This review summarizes major technical approaches for studying single-cell function and structure in the live brain as they are applied today in neuroscience. Given there are many excellent reviews on the topic (Brette and Destexhe, 2012; Duque, 2006; Lee et al., 2006; Lee and Brecht, 2018; Preston-Ferrer and Burgalossi, 2018; Vertes and Stackman, 2011), we chose to provide an operational analysis of the methods available to facilitate their application to particular problems at hand. The main references consulted for identifying feature ranges are summarized in the Supplementary Table 1, but others are included below.

\section{Definitions and uses}

The basic concept behind any single-cell study in vivo is the functional characterization of individual cell types either spontaneously or in response to different types of stimulations. The region and the question of interest will determine the preparation (anesthetized, head fixed or freely moving) and the functional assay adopted. For example, studies in primary sensory cortices typically focus on receptive field characterization (Kelly and Van Essen, 1974; Crochet and Petersen, 2006), whereas hippocampal single-cell activities are evaluated with respect to ongoing local field potential (LFP) by establishing the relationship between firing and oscillations in the theta, gamma and highfrequency bands (Klausberger et al., 2003). For a proper identification of cell identity, labeling is required for post hoc anatomical characterization.

In this section we define the different methods and summarize their specific features (Fig. 1).

\subsection{Intracellular sharp}

Intracellular recordings are established blindly with so-called sharp micropipettes of $0.01-0.1 \mu \mathrm{m}$ tip diameter and high impedances of the order of 70-120 M (Brette and Destexhe, 2012). Cell penetration is achieved by vibrating the micropipette tips with large and brief current pulses (buzzes) that exploit the capacitance neutralization circuit (Brette and Destexhe, 2012; Konopacki et al., 2003). This technique allows accessing the intracellular membrane potential, thus providing information not only about neuronal firing (spikes $>50-60 \mathrm{mV}$ ) but also on subthreshold synaptic activity. Different cell types, including glial cells, can be recorded with this method (Kelly and Van Essen, 1974) (English et al., 2014; Fernandez-Lamo et al., 2019; Kamondi et al., 1998; Quilichini et al., 2010; Sik et al., 1995; Steriade et al., 2001; Valero et al., 2015; Ylinen et al., 1995). Sharp recordings are blind by definition and the ability to impale a cell depends on a combination of factors. Regions with dense neuronal packaging like the hippocampal cell layers, or bigger cells such as large pyramidal neurons are easier to catch. Labeling is achieved by iontophoresis of charged dyes or tracers with repetitive current pulses. Although the cell is penetrated, there is poor dialysis of cytoplasmic content and the method is compatible with post hoc immunohistochemistry (see Section 4). Some drugs used at high concentration in sharp pipettes can leak very slowly into the cell facilitating intracellular pharmacological experiments (Valero et al., 2017). Sharp recordings are very sensitive to mechanical instabilities, thus they are mostly performed under anesthesia or highly stable conditions. They can be also obtained in awake, head-fixed or freely moving conditions (English et al., 2014; Fee, 2000; Steriade et al., 2001) but these recordings are typically shorter.

\subsection{Juxtacellular}

The juxtacellular configuration is defined by a close apposition between a midsize micropipette tip $(0.5-1.5 \mu \mathrm{m}, 10-25 \mathrm{M} \Omega)$ and the outer cell membrane (Pinault, 1996). In this configuration, the micropipette is moved blindly towards the cell while monitoring the amplitude of action potentials $(0.5-5 \mathrm{mV})$. This makes the original juxtacellular technique biased for cells that fire, either spontaneously or in response to stimulation (Pinault, 1996). Since recording of neuronal firing proceeds extracellularly, this configuration is considered non-invasive. Indeed, many researchers choose to adjust proximity to the cell just for labeling to avoid interfering with the spontaneous firing pattern (Brown et al., 2009; Dempsey et al., 2015; Duque, 2006; Klausberger et al., 2003; Salib et al., 2019; Takács et al., 2012; Unal et al., 2018; Viney et al., 2013). The juxtacellular method may be challenging when applied to sparse firing cells which are packed in a compact layer, since recording sometimes cannot be unequivocally matched with the labeled neuron (Arszovszki et al., 2014). Some researchers exploit patch-like pipettes (1.5-2.5 $\mu \mathrm{m}, 4-6 \mathrm{M} \Omega$ ) for juxtacellular approaches to monitor for changes of tip impedance as a clear indication of cell contact (Burgalossi et al., 2011; Coletta et al., 2018; de Kock and Sakmann, 2009; Diamantaki et al., 2018; Herfst et al., 2012; Houweling et al., 2010; Houweling and Brecht, 2008; Narayanan et al., 2014; Tang et al., 2014). This makes the searching approach unbiased for spiking neurons.

Labeling is achieved by passing repetitive high-amplitude current pulses that destabilize the membrane and produce micro-pores, as noted by the increase in the background noise and deformed action potential waveforms (Herfst et al., 2012; Narayanan et al., 2014; Pinault, 1996; Tang et al., 2014). These changes are typically reversible and reestablishment of initial waveform and firing rate are good indicators for successful post hoc histological recovery (Duque, 2006; Herfst et al., 2012; Narayanan et al., 2014; Pinault, 1996). The juxtacellular method allows for subsequent neurochemical studies of singlecell types using immunolabeling.

\subsection{Loose-patch}

For the purpose of this review, we consider as loose-patch any approach exploiting pressure maneuvers associated with patch-clamp approaches to establish contact with the cell (Joshi and Hawken, 2006). It usually involves the release of positive pressure followed by mild suction when the pipette is already in contact with the target, which is detected by changes in impedance (Joshi and Hawken, 2006; Judkewitz et al., 2009). While this strategy prevents for the need of firing to 
A
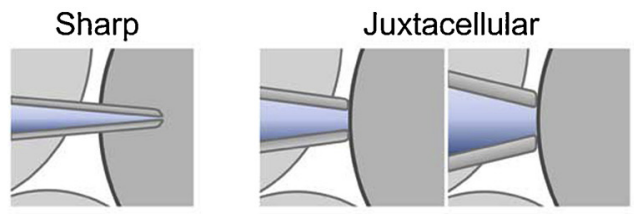

Loose-patch Whole-cell

Sharp

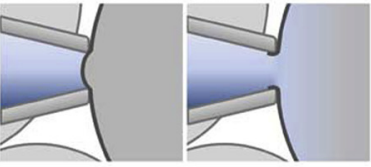

Patch
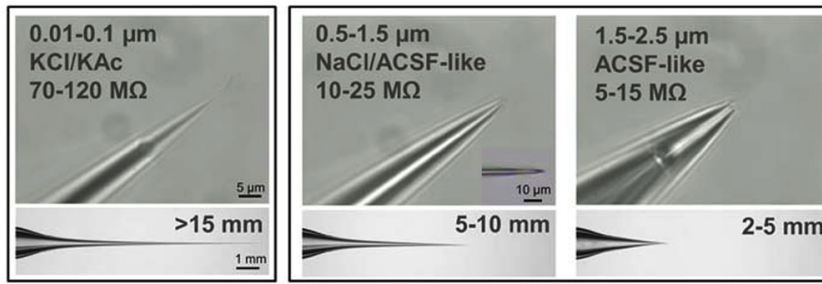

Tip diameter Internal solution Impedance

Taper length

\section{B}

\begin{tabular}{|l|c|c|c|c|c|}
\hline & Sharp & $\begin{array}{c}\text { Juxta } \\
\text { 'sharp' }\end{array}$ & $\begin{array}{c}\text { Juxta } \\
\text { patch-like }\end{array}$ & $\begin{array}{c}\text { Loose- } \\
\text { patch }\end{array}$ & $\begin{array}{c}\text { Whole- } \\
\text { cell }\end{array}$ \\
\hline Two-photon guidance (shadow) & & & $\checkmark$ & $\checkmark \checkmark$ & $\checkmark \checkmark \checkmark$ \\
\hline Deep structures & $\checkmark \checkmark$ & $\checkmark \checkmark$ & $\checkmark$ & $\checkmark$ & $\checkmark$ \\
\hline Bias for firing cells & & $\checkmark$ & & & \\
\hline Membrane potential & $\checkmark$ & & & & $\checkmark$ \\
\hline Voltage-clamp & & & & & $\checkmark$ \\
\hline Intracellular pharmacology & $\checkmark$ & & & & $\checkmark$ \\
\hline Morphological dyes/tracers & $\checkmark$ & $\checkmark$ & $\checkmark$ & $\checkmark$ & $\checkmark$ \\
\hline Plasmid DNA & & $\checkmark$ & $\checkmark \checkmark$ & $\checkmark \checkmark$ & $\checkmark \checkmark \checkmark$ \\
\hline Post hoc immunostaining & $\checkmark \checkmark$ & $\checkmark \checkmark$ & $\checkmark \checkmark$ & $\checkmark \checkmark$ & $\checkmark *$ \\
\hline Morphological reconstruction & $\checkmark$ & $\checkmark$ & $\checkmark$ & $\checkmark$ & $\checkmark$ \\
\hline Extracellular spillover (dyes/tracers) & & & & $\checkmark$ & $\checkmark \checkmark$ \\
\hline Suitability for awake recording & $\checkmark$ & $\checkmark \checkmark$ & $\checkmark \checkmark$ & $\checkmark$ & $\checkmark$ \\
\hline
\end{tabular}

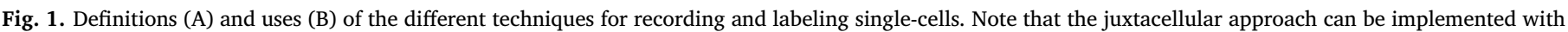

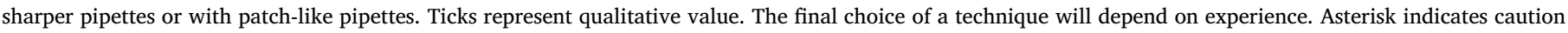
due to dialysis.

identify a cell (Joshi and Hawken, 2006), the method is still relying on recording action potentials (0.5-5 $\mathrm{mV}$ amplitude). Establishing a loose or a tighter seal with the cell is judged by impedance increases in the order of 3-10 fold. A possible withdrawal of applying pressure is the spillover of the tracer. However, this can be exploited for visually targeting cells while extracellularly expelling a fluorescent dye to get a shadow image by two-photon microscopy (Cohen et al., 2013; Judkewitz et al., 2009; Kitamura et al., 2008; Marshel et al., 2010; Nevian and Helmchen, 2007; Oyama et al., 2013). As in juxtacellular approaches, cell labeling is achieved by electroporation. Given that in this configuration the cytoplasmic composition is not altered, labeling can be combined with post hoc immunochemistry.

\subsection{Whole-cell recordings}

Whole-cell recordings in vivo can be established after breaking a giga-ohm seal with ramping suction (Jouhanneau and Poulet, 2019; Lee et al., 2009; Margrie et al., 2002; Wang et al., 2016). Other strategies for opening the membrane, like amphotericin perforation, have also been applied in vivo (Wang et al., 2016). As in loose-patch, whole-cell recordings can be done visually, assisted by two-photon imaging (Jouhanneau and Poulet, 2019; Kitamura et al., 2008; Polack et al., 2013); however they are obtained mostly in a blind manner (Brecht and Sakmann, 2002; Cohen et al., 2017; Coletta et al., 2018; Epsztein et al., 2011; Harvey et al., 2009; Hulse et al., 2016a; Lee et al., 2009; Maier et al., 2011; Margrie et al., 2002; Oberlaender et al., 2012; Poulet and
Petersen, 2008; Rancz et al., 2011; Wang et al., 2016). Since whole-cell recordings are intracellular, they permit the study of subthreshold membrane potentials and spikes ( $>50 \mathrm{mV}$ ), similar to sharp recordings (Cohen et al., 2017; Crochet and Petersen, 2006; Epsztein et al., 2011; Harvey et al., 2009; Maier et al., 2011). A major feature of the technique is the ability to quickly dialyze recorded neurons, which sometimes complicates subsequent neurochemical characterization but enables intracellular pharmacological studies (Hulse et al., 2016a; Margrie et al., 2002; Wang et al., 2016). With whole-cell access, dyes or tracers diffuse freely in the cell favoring anatomical reconstructions.

\subsection{Choosing the best approach}

In choosing one approach or another, researchers need to consider the pros and cons of each technique in relationship with the questions at hand. For instance, if membrane potential dynamics is a critical variable to measure, only sharp and whole-cell recordings will help. However, space-clamp errors in recording synaptic events from distant and elaborated dendritic trees will be a bigger issue for sharp than for whole-cell recordings (but see Spruston et al., 1993). In contrast, reaching structures deep into the brain such as the thalamus will be easier with sharper long taper pipettes. Similarly, to target cells under visual guidance in vivo is better to use loose-patch and whole-cell approaches because patch-like pipettes and pressure maneuvers facilitate tissue clearance and shadowing. While all these methods are typically used to target the soma of individual cells, dendritic recordings can be 
also established (Kamondi et al., 1998; Kitamura et al., 2008). Fig. 1B summarizes some specific features of each technique to help experimenter to make informed decisions.

\section{Technical approaches for single-cell recordings}

The best pipette to successfully target single-cells depends on the approach used, but there are common principles. Micropipettes are basically made from borosilicate glass capillaries with an inner filament to facilitate subsequent filling. Their dimension varies substantially, but most labs choose between $1.5-2.2 \mathrm{~mm}$ and $0.8-1 \mathrm{~mm}$ for outer and inner diameters, respectively. Glass capillaries are pulled, either horizontally or vertically, to obtain a pipette with specific tip diameter and taper length (Oesterle, 2018). Some researchers choose to bevel the tip after pulling to achieve a smooth surface that avoid damaging cells (Moore et al., 2015; Oyama et al., 2013). The diameter and shape of the pipette tip differ amongst approaches, but can also be adjusted depending for instance on the cell size (thinner tips for smaller cells) or the region of interest (deeper regions require longer pipette tapers to avoid over-pressing the brain).

A critical feature for each configuration is the pipette impedance (highest for sharp intracellular, lowest for whole cell recordings), which depends not only on the shape, but also on the filling. Filling solutions could be either non-physiological (i.e. high salt concentration such as potassium acetate or chloride; $\mathrm{K}-\mathrm{Ac}$ and $\mathrm{KCl}$, respectively) or physiological (i.e. $\mathrm{NaCl}$, extracellular solutions mimicking intracellular-like solutions or the artificial cerebrospinal fluid, ACSF) depending on the approach. Choosing one type of solution or the other typically depends on the pipette tip and the approach. The wider the tip the lower the impedance and therefore physiological-like solutions can be used. Using extracellular or intracellular-like solutions will depend on the approach, like for instance juxtacellular versus whole-cell intracellular recordings.

Micromanipulators are always required for advancing the pipette, but their model depends on the preparation and the recording configuration. For anesthetized and awake head-fixed preparations, standard manipulators are coupled to the stereotaxic frame. For freely moving recordings, microdrives should be head-mounted (Valero and English, 2019). A variety of head-mounted drives have been developed for extracellular (Korshunov, 2006; Pager, 1984), whole-cell (Epsztein et al., 2011; Lee et al., 2009; Long and Lee, 2012), juxtacellular (Averkin et al., 2016; Burgalossi et al., 2011; Coletta et al., 2018; Diamantaki et al., 2018; Herfst et al., 2012; Joshi et al., 2017; Katona et al., 2017; Lapray et al., 2012; Tang et al., 2014; Valero et al., 2015) and sharp recording applications (English et al., 2014; Long et al., 2010). Driving could be manual, motorized, piezoelectric or hydraulic according to the model. Loose-patch and whole-cell approaches use dedicated pipette holders that permit to apply internal pressure to the pipette.

Below we describe protocols for successful blind recordings in each configuration. In each case, we highlight some basic concepts, the characteristic of the best micropipettes used and the specific recording steps. Labeling procedures are discussed in the next section. Fig. 2 summarizes the main critical steps for obtaining successful single-cell recordings in each configuration.

\subsection{Sharp intracellular recordings}

Recording with sharp pipettes is the oldest method to access membrane potential fluctuations and the master approach in vivo before patch-clamp (Contreras and Steriade, 1995; Friedlander et al., 1979; Núñez et al., 1987; Steriade et al., 1993a,b). While cortical neurons can be also recorded, this technique is especially suitable for deep brain structures. Sharp recordings are mostly done in currentclamp configuration. Voltage-clamp cannot be established due to the high impedance of the pipette. Sharp pipettes can record large extracellular signals such as evoked potentials but not ongoing LFP oscillations. In addition, sharp electrodes sometimes can damage the membrane resulting in a non-selective leak current that deteriorates recordings. The typical hallmark of a leaky cell is the inability to control the membrane potential by current injection.

Micropipette: In our hands, the best pipette shape is a long straight taper of 10-15 mm or even larger so that at the level of the brain surface the pipette width is $<100 \mu \mathrm{m}$. Pipettes with $50-60 \mathrm{M} \Omega$ may be very invasive for cells, especially for neurons with small somata, while those with more than $150 \mathrm{M} \Omega$ tend to be electrically unstable (nonlinear) and noisy. While the best pipette has to be determined empirically, we typically chose those with about 80-90 $\mathrm{M} \Omega$ to target hippocampal cells.

Filling solution: Pipettes are typically filled with potassium-based solutions ( $\mathrm{KCl}$ or $\mathrm{KAc}$ in the order of Molar concentration). Tracers typically used are biocytin or Neurobiotin at $1-3 \%$. To avoid bubbles, the pipette tip can be initially backfilled by capillary action.

Protocol: Since sharp recordings are very sensitive to mechanical instabilities, they are mostly performed under anesthesia. They can be also obtained in awake, head-fixed and freely moving conditions but these recordings are typically shorter. For recording under anesthesia, draining the cisterna magna is typically implemented to gain stability (Liu and Duff, 2008; Sik et al., 1995; Ylinen et al., 1995). Some other procedures for mechanical stabilization can further reduce brain movements due to respiration and heart beat (Konopacki et al., 2003).

Next, we summarize steps for successful sharp recordings in rodents (Fig. 2A):

1) Once the micropipette is ready to advance into the brain, open a very small window at the dura with a bent needle.

2) Establish the zero level from the brain surface and start penetrating the brain under electrophysiological control. Clear the pipette tip many times by buzzing while penetrating the first microns into the brain. Buzzing should be brief $(1-2 \mathrm{~ms}$ at most $5 \mathrm{~ms})$ with the pipette capacitance neutralized. Correct the pipette offset at $0 \mathrm{mV}$.

3) Advance in small accelerated steps (initially around $20-30 \mu \mathrm{m}$ ) while controling the pipette impedance and offset. The polarity of current pulses should be considered in order to avoid spillover of charged dyes or tracers. When targeting deep structures, it is recommended to start with $90-150 \mathrm{M} \Omega$ pipettes since they typically break while passing through the callosum and brain fissures.

4) If possible, follow neurophysiological signatures for reference. A major feature of sharp recordings is their high noise level that precludes recording of ongoing LFP activities. Instead, since recordings are established in current-clamp mode, large extracellular evoked potentials can be continuously monitored for guidance.

5) While advancing, clear the micropipette from time to time by buzzing. Control the offset, impedance and capacitance neutralization.

6) Check for cells above your region of interest. That helps to gain confidence in the pipette and to establish landmarks (e.g. granular cortical layers; callosum, etc...). For instance, while on our way to the dorsal hippocampus in rats we typically catch cells in deep cortical layers $(600-800 \mu \mathrm{m}$ from surface in rats).

7) In acute preparations (awake head-fixed and anesthesia) it is recommended to add warm agar or agarose $(2-3 \%)$ solutions around the craniotomy, once the pipette is validated. Hot wax $\left(50^{\circ} \mathrm{C}\right.$ maximum) or silicone can also be used.

8) Once at the desired region (according to evoked potential hallmarks or any other criterion), move slowly back and forth and buzz the pipette many times to start searching. It is useful to apply step currents $(-0.05$ to $-0.1 \mathrm{nA})$ while advancing in small steps for cells and to rely on changes of the tip impedance which are indicative of establishing contact.

9) If penetration is successful, the potential will drop from zero to more than $-40 \mathrm{mV}$ just after a buzz and large action potentials of tens of millivolts will be visible. Sometimes, penetration is achieved without requiring buzzing. Once into a cell, inject some 


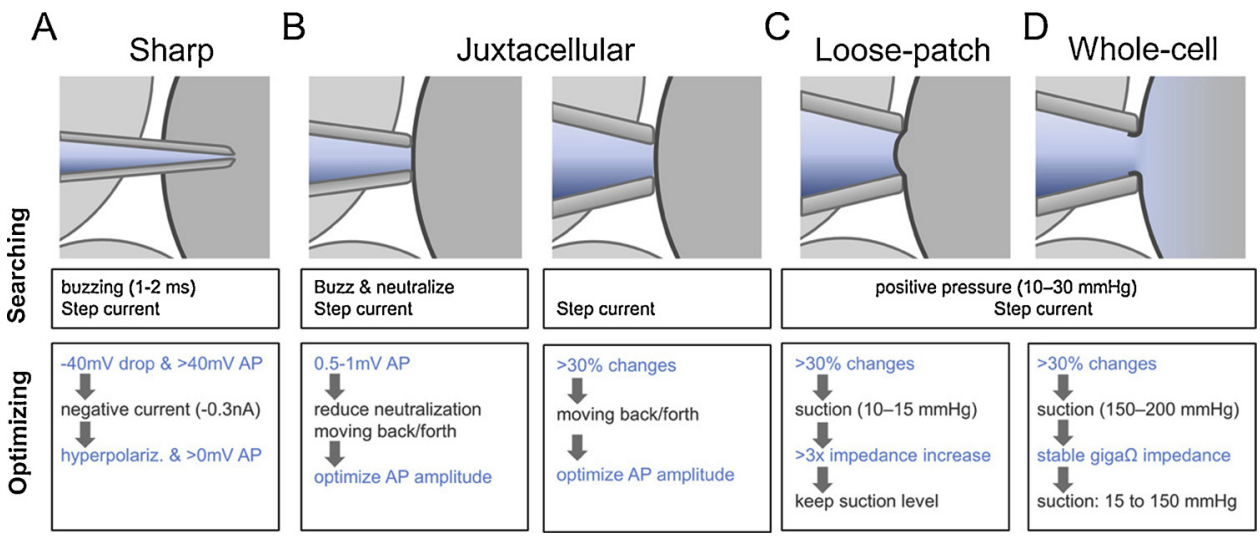

Fig. 2. Summary of the main maneuvers for single cell recording in the different configurations. AP, action potentials.

sustained current into the cell ( -0.2 to $-0.3 \mathrm{nA}$ ) while monitoring the resting membrane potential and input resistance. It may be helpful to retract the pipette just a bit from the cell. A good recording will hyperpolarize (holding current can be reduced), action potentials will increase in amplitude and become overshooting (passing the $0 \mathrm{mV}$ level) and membrane time constant will be evident in response to the current pulse.

10) Stay in place and proceed with functional characterization.

\subsection{Juxtacellular recordings}

Technically, the juxtacellular approach is obtained in current-clamp mode thus providing an extracellular signature of action potentials emitted by single-cells. When juxtaposing on the target cell, the spike waveform switches from negative to a characteristic positive shape. The use of the capacitance neutralization in current-clamp mode helps to identify neurons. This practice is more typically used with long and sharp pipettes than with patch-like pipettes. Many researchers opt for recording lower amplitude spikes first $(0.5-1 \mathrm{mV})$ and then moving further for labeling ( $>2 \mathrm{mV}$ ) (Brown et al., 2009; Dempsey et al., 2015; Duque, 2006; Klausberger et al., 2003; Takács et al., 2012; Unal et al., 2018; Viney et al., 2013).

Juxtacellular approaches also permit access to LFP signals for guidance. For instance, a parallel multisite silicon probe can help to establish the micropipette depth by comparing LFP signals across layers. In some cases, using electrical stimulation of input pathways may help to guide penetration by evoked potentials. Others learn to functionally characterize the cell-type of interest beforehand by establishing critical hallmarks using electrical or optogenetic stimulation to disclose projecting cells (Steriade et al., 1993a,b; Fernandez-Lamo et al., 2019).

Micropipette: There are two major schools for juxtacellular approaches. In the Pinault school the best micropipette shape is a slender taper with a sharp cone at the tip (Fig. 2B, left). Typically, it ranges from 0.5 to $1.5 \mu \mathrm{m}$, which depending on the filling solution can give impedances between 10 and $25 \mathrm{M} \Omega$. Other researchers are more skilled at using modified patch-like pipettes with tip diameter from 1.5 to 2.5 $\mu \mathrm{m}$ (4-6 M $\Omega$ ) for juxtacellular approaches (Fig. 2B, right).

Filling solution: Filling solutions are usually physiological (i.e. $\mathrm{NaCl}$ $0.5 \mathrm{M}$ in the first school, and Ringer solutions or ACSF in the second). Tracers are typically used at $1-3 \%$ and can be added to the stored solution. While these compounds can slightly alter the $\mathrm{pH}$, in our experience we found no difference by adding them the same day of recording. Some researchers use $0.2-0.5 \mu \mathrm{m}$ filters to make aliquots of the solution which are stored for several months at $-20{ }^{\circ} \mathrm{C}$.

Protocol: Once the micropipette is ready to advance into the brain, the protocol is similar for recordings under anesthesia, head-fixed or freely moving conditions (Fig. 2B).
1) Open the dura. Some researchers choose instead to penetrate the dura with the pipette tip whenever possible (Averkin et al., 2016; Herfst et al., 2012; Houweling et al., 2010; Houweling and Brecht, 2008).

2) Establish the zero level from brain surface and start penetrating the brain. In juxtacellular recordings, it is recommended to double the voltage micropipette channel in a wideband and a high-pass filtered $(>300 \mathrm{~Hz})$ channel for monitoring spikes.

3) Advance in small steps while controlling the pipette signal, offset and impedance (with pulses of $200-500 \mathrm{~ms}$ ). As in sharp recordings, use negative current pulses to avoid spillover of charged tracers such as Neurobiotin, but see Section 3.1.

4) Follow neurophysiological signals for reference. Either evoked potential or LFP oscillations can be recorded with juxtacellular pipettes.

5) While using high-impedance pipette, clear the tip from time to time by buzzing $(1 \mathrm{~ms})$. This practice is not recommended for patch-like pipettes since accidental cell staining may occur. Control the pipette offset, impedance and capacitance, which should increase while penetrating the brain.

6) Check for cells over the region of interest to test for the pipette behavior and to establish clear landmarks.

7) At this intermediate point, it may be useful to add warm agar, agarose or wax in acute preparations. Keep moving downward while checking pipette electrical parameters.

8) Once you reach the vicinity of the desired region (as judged by LFP or other criteria) start moving slowly while following searching criteria mentioned above. Be aware that this practice will make the juxtacellular approach biased for firing cells. You can choose instead to monitor impedance changes with step current pulses.

9) Once you see small positive action potentials $(0.5-1 \mathrm{mV}$; more easily visible at the high-pass channel), reduce neutralization to avoid damage in case you are using sharper pipettes. Keep moving back and forth while monitoring the spike amplitude for optimization of recording conditions.

10) Stay in place and proceed with functional characterization.

\subsection{Loose-patch}

Loose-patch, similar to the juxtacellular method, allows for assessing firing activity of individual cells (Joshi and Hawken, 2006). Applying mild pressure is a major concept behind loose-patch. Positive pressure is used to clear up the micropipette tip while advancing into the brain and negative pressure to suck the cell membrane in order to establish a loose seal. Adjusting the amount of pressure is critical to avoid penetrating the cell.

To identify the proximity of a cell membrane, step pulses are used to monitor tip resistance. That makes loose-patch not dependent on action 
potentials to target cells and therefore it is less biased. However, it is important to note that any approach has a bias either due to morphological or procedural factors (Menendez de la Prida et al., 2002). Importantly, even though the loose-patch configuration is said not to be biased for firing cells, only spiking activity can be recorded.

Micropipettes: Tip diameter can range widely from 0.5 to $2.5 \mu \mathrm{m}$. The taper length can vary but shapes are typically similar to patch pipettes (Fig. 2C). Impedances are in the range of 5-15 M 2 .

Filling solution: Filling solutions are typically ACSF-like, and the dye/ tracer is added in similar concentrations as in juxtacellular or sharp. Charged low molecular compounds $(<3000 \mathrm{MW})$ such as dextran amines and large molecules like plasmids can be also be injected with larger pipettes (see Section 4).

Protocol: The approach is similar as for juxtacellular recordings, with the exception of some sequential maneuvers required to establish the seal using pressure (Fig. 2C).

1) Open the dura as mentioned before.

2) Introduce the pipette into the brain with sustained positive pressure $(10-30 \mathrm{~mm} \mathrm{Hg}$ ) while monitoring step deflections. In case of targeting deep brain regions, use larger initial pressures (200-300 $\mathrm{mm} \mathrm{Hg}$ ). Pressure is typically applied using a syringe coupled to the pipette holder with a silicone tube. Some researchers chose to apply pressure directly by mouth, while others choose to calibrate the pressure per syringe volume or using digital pressure gauge. Establish zero level at surface and compensate capacitance and resistance.

3) Advance while controlling the pipette offset and impedance (with step current pulses of $200-500 \mathrm{~ms}$ ). In the loose-patch configuration it is recommended to move relatively fast to the desired region and stay in place for few minutes to allow for stabilization.

4) Monitoring extracellular potentials at the pipette tip will depend on the filling solution, noise level and the amount of pressure used for clearing.

5) Advance in small steps towards the region of interest while monitoring step responses and pipette offset.

6) A major weakness of the loose-patch configuration is that pipettes are not easily reused after sucking (though some researchers succeed in doing so), thus cells on the way to target regions should be avoided.

7) In head-fixed preparations, consider adding warm agar as mentioned before. Since the pipette taper is about $50-100 \mu \mathrm{m}$, a cone of access is drawn in the agar and can be used for subsequent penetrations.

8) Once you reach the vicinity of the desired region start moving very slowly and check for changes of impedance indicative of establishing contact with a putative cell. Release pressure and apply some mild suction (10-25 mm Hg). With higher negative pressures a cell-attached configuration can be established. At this point, an increase of tip resistance of 3-10 times the original value may be indicative of a loose seal. Keep the pressure and check for spontaneous action potential firing. Be aware that the loose-patch approach is juxtacellular and therefore spikes are required for confirmation. Cells can remain silent for a while, so be patient if the seal response remains stable.

9) Sucking pressure can be slightly adjusted while monitoring positive action potentials but at risk of damaging the cell.

10) Proceed with functional characterization.

\subsection{Whole-cell recordings}

The approach is similar to the loose-patch, except for suction parameters aimed to establish a tighter seal and posterior maneuvers intended to break it. In most cases, whole-cell in vivo may be limited to more superficial penetrations (Fig. 2D), although it can be also adjusted to target deep regions (Brecht and Sakmann, 2002; Cohen et al., 2017;
Coletta et al., 2018; Epsztein et al., 2011; Harvey et al., 2009; Hulse et al., 2016b; Lee et al., 2009; Maier et al., 2011; Oberlaender et al., 2012; Wang et al., 2016).

Micropipettes: The tip diameter can range widely from 1 to $3 \mu \mathrm{m}$. The taper length can vary but shapes are typically similar to patch pipettes described before (Fig. 2C). Impedances are in the range of 1-8 M 2 .

Filling solution: Filling solutions are typically ACSF-like. The dye/ tracer is added in lower concentrations than in other approaches $(<1 \%)$.

Protocol: Follow the same steps 1-7 as in loose-patch

1) Aim for a giga-ohm seal (cell-attached) by quickly removing the positive pressure followed by suction in a range of $150-200 \mathrm{~mm} \mathrm{Hg}$.

2) After the seal resistance is stabilized, the patch membrane is broken by applying ramping suction from 15 to $150 \mathrm{~mm} \mathrm{Hg}$.

3) Once in whole-cell, membrane potential fluctuations can be recorded. Using pipettes with low impedance and capacitance values permit voltage-clamp measurements of synaptic currents so that the technique is quite versatile.

These procedures can be made automatic (Suk et al., 2019). In some freely moving applications, it is necessary to patch a cell first, then 'anchor' the pipette in place with cement before waking up and releasing the animal or freely moving recordings (Lee et al., 2009, 2006; see also Valero and English, 2019).

\section{Technical approaches for labeling single-cells}

Once the functional characterization is completed, single-cells are filled with dyes or tracers for subsequent morphological and neurochemical studies. In most cases, biocytin or Neurobiotin are used, but other tracers such as biotinylated dextrans or fluorescent dyes (e.g. the Alexa family) and larger molecules such as DNA plasmids can be exploited (Supplementary Table 1). Individual cells can be also filled with functional reporters of activity, such as calcium or voltage-sensitive dyes (Nevian and Helmchen, 2007; Willadt et al., 2014). We first describe the general steps to deliver morphological dyes with specific notes for each configuration. Given that in vivo plasmid electroporation requires specific approaches, they are discussed separately. For microinjecting functional dyes, we refer to other reviews (Peterka et al., 2011).

\subsection{Morphological dyes or tracers}

Single-cells are typically labeled in vivo with biocytin (biotinyl-Llysine) or Neurobiotin (biotinamide hydrochloride). These tracers are diluted in the internal solution of the pipette at concentrations around $2-3 \%(0.5 \%$ in whole cell recordings). Neurobiotin is more soluble than biocytin (Kita and Armstrong, 1991). To expel them, current pulses should be applied through the micropipette while monitoring the cell response. Neurobiotin is selectively ejected by positive current while biocytin can be ejected by both positive and negative current (Kita and Armstrong, 1991). The amplitude of the injected current depends on the configuration used. Quality of labelling can be predicted from the cell behavior during the process, as diffusion of the tracer along cell processes will depend on the survival time. Both biocytin and Neurobiotin tend to degrade over days, for longer survival periods biotinylated dextran amines (BDA) are recommended (although not 100\% effective either), since they are not metabolized (Kita and Armstrong, 1991; Unal et al., 2018). There is also an improved version of Neurobiotin (Neurobiotin plus), with longer half-life. Choosing one or another can be tested empirically. For instance Salib et al. (2019) used in separate experiments either $3 \%$ neurobiotin or 10\% BDA (3000 MW) dissolved in $0.5 \mathrm{M} \mathrm{NaCl}$ for juxtacellular labelling.

Below we describe the general steps for labeling single-cells in the juxtacellular, loose-patch and sharp intracellular configurations with 
A

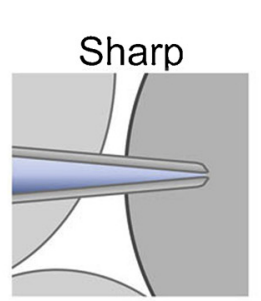

B
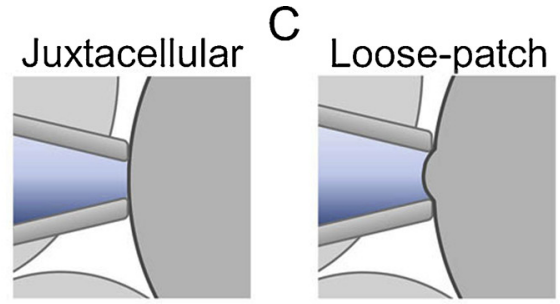

$\mathrm{D}$
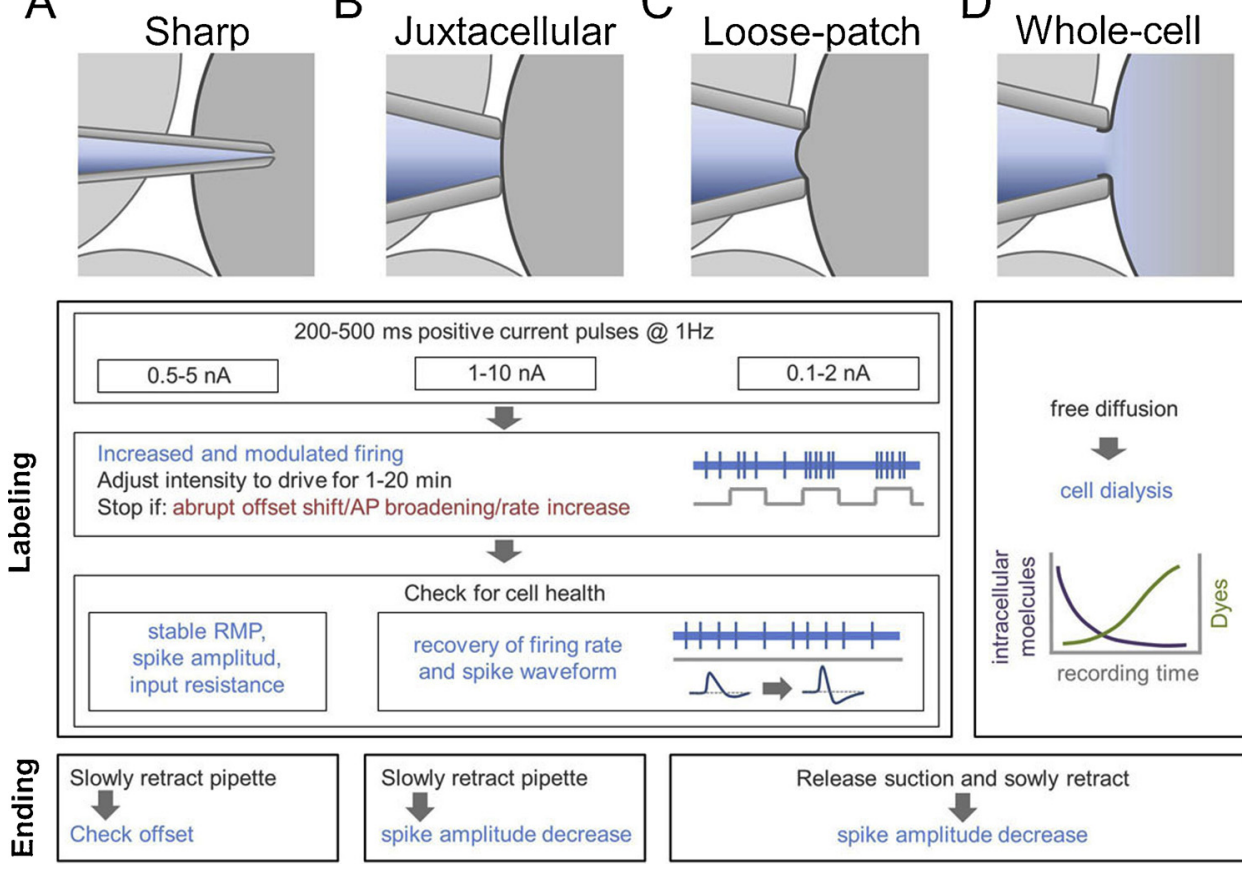

200-500 ms positive current pulses@1 $1 \mathrm{~Hz}$

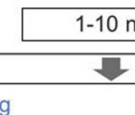

$1-10 \mathrm{nA}$

!

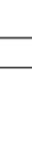

\section{$0.1-2 \mathrm{nA}$}
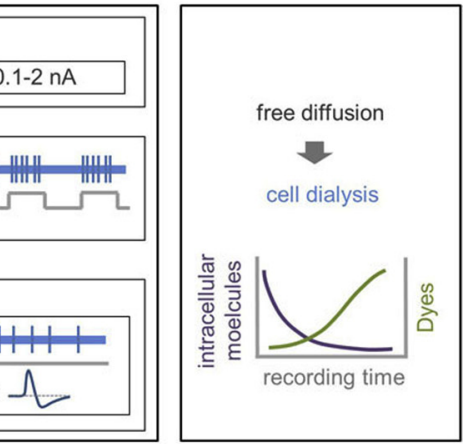

Check for cell health

\section{recovery of firing rate} and spike waveform
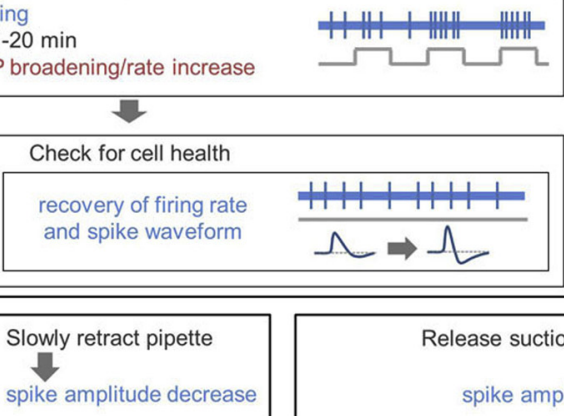

Release suction and sowly retract

$\checkmark$

spike amplitude decrease

Fig. 3. Summary of the main maneuvers for single cell labeling in the different configurations.

specific details associated to each approach. Since labeling may be disturbing for cells, especially in the juxtacellular mode, it is recommended to characterize spontaneous activity beforehand, and check whether the firing rate and spike waveform recovers if additional neurophysiological characterization is required. In whole-cell recordings, the cytoplasmic content is dialyzed over time and that may compromise immunolabeling of some proteins. This should be carefully considered if additional neurochemical characterization is implemented (causing false negatives). Because in this configuration dyes and tracers diffuse freely into the cell, morphological reconstruction is facilitated.

Fig. 3 summarizes the main critical points for obtaining successful single-cell labeling in each configuration.

1) Once inside (sharp, whole-cell) or in contact with the cell (juxtacellular, losse-patch) start applying positive current pulses (200-500 ms at $1 \mathrm{~Hz}$ ) of different amplitudes according to the configuration. Sharp: Start with $0.5-5 \mathrm{nA}$ just to expel the tracer by iontophoresis. Juxtacellular/ Loose-patch: First optimize the spike amplitude to $>2 \mathrm{mV}$ by moving slightly to guarantee close apposition onto the cell surface. Then, gradually increase intensity (usually from 1 to $10 \mathrm{nA}$ ).

2) Check for action potential waveform and spike rate. During these pulses a bridge balance is very useful to monitor entrainment and amplitude of the action potentials on alternate current pulses.

3) Adjust the pulse amplitude so that you still drive cell firing. Sharp: Keep an intermediate firing level. Juxtacellular/Loose-patch: Typically reduce to 1-5 nA, and adjust bridge balance accordingly.

4) Any abrupt change, including offset shifts, sudden firing rate increases or action potential broadening are indicative of cellular damage (Narayanan et al., 2014; Pinault, 1996). If this happens, reduce the injected current and consider retracting the pipette just a bit (not recommended when cells are densely packed because of the risk of labeling a different cell). If intracellularly, consider injecting some steady negative current to stabilize the cell.

5) After 2-20 min of labeling, stop the procedure and check for the recovery of cell spontaneous activity, which can take several minutes (Duque, 2006; Pinault, 1996). In juxtacellular and loosepatch, the firing rate increases and the spike waveform change after labeling (Narayanan et al., 2014). If the cell is healthy, these changes reverse, which is indicative of successful electroporation. For sharp intracellular labeling, the cell should remain stable in terms of resting membrane potential, input resistance and spike amplitude.

6) For juxtacellular and loose-patch, try to fill the cell again after a short pause. As Pinault said in his classical paper, injection of dyes consists of "tickling the investigated cell as long as necessary", typically along minutes (Pinault, 1996).

7) If juxtacellular labeling was preceded by extracellular recordings, it is recommended to re-characterize the cell after labeling to be sure that it is the same neuron (Pinault, 1996).

8) After completing labeling, retract the electrode slowly while monitoring cell firing. If in loose-patch, release suction and move away from the cell. For both juxtacellular and loose-patch, spike amplitude should decrease. In sharp recordings, the pipette offset should returns to zero. If not, make note of the offset to correct membrane potential values.

9) After having retracted the pipette, allow the dye to diffuse within the cell. Different labs have reported from 1 to $12 \mathrm{~h}$ post-labeling, or even longer periods of days for identifying projecting cells (Arszovszki et al., 2014; Oberlaender et al., 2012; Salib et al., 2019; Unal et al., 2018). Depending on tracer used different post-labeling time can be leveraged for optimizing results (see below).

10) Euthanize the animal according to your local procedures and start with intracardiac perfusion (typically $4 \%$ paraformaldehyde in PBS). Using freshly added $0.05 \%$ glutaraldehyde improves immunoreactivity for many antibodies.

11) Remove the brain and store it overnight at $4{ }^{\circ} \mathrm{C}$ in $4 \%$ paraformaldehyde. Then move the fixed brain to PBS and proceed with sectioning. Be aware that immunoreactivity of some proteins may be affected by overfixation. Avoid post-fixing with glutaraldehyde since it can cause lower immunoreactivity.

It is recommended to label only one cell per animal/hemisphere in order to reduce ambiguity. This is not always possible though, especially when cells are lost before completing the procedure. While using tracers that are metabolized within $24 \mathrm{~h}$, experiment could be repeated 
over next days in case researchers are not convinced on recording or labeling quality. It is very important to make notes along the experiment to help in identifying different attempts. If using BDA tracers caution should be taken to avoid attempting same location on multiple days. Sometimes, cells are labelled 'spontaneously' (for instance during buzzing) but dye intensity is lower in these cases and confined to the soma (Duque, 2006; Pinault, 1996). If the recorded cell dies during labeling or when retracting the pipette, some staining could be detected in the soma but it will usually show fragmented dendritic profiles (Pinault, 1996). Successfully labeled cells typically exhibit the soma and a large part of the dendritic and even axonal arborizations. If the soma and dendrites are strongly labeled there is a high chance that the axon is labeled sufficiently well.

\subsection{Plasmid electroporation}

DNA vectors can be electroporated in single-cells in vivo after completing functional characterization. Expression is usually achieved after $24 \mathrm{~h}$ or over the next days and therefore this approach is typically followed up by complementary techniques. For instance, it allows for longitudinal functional studies (Cohen et al., 2013) or single-cell initiated tracing (Marshel et al., 2010; Rancz et al., 2011; Wertz et al., 2015; see also Schwarz and Remy, 2019). Since DNA encoding fluorescent reporters will be constitutively integrated into the cell, this technique is especially suitable for detailed morphological reconstruction. Plasmids that have been successfully used for that purpose typically exploit ubiquitous promoters such as CAG or CBA (Cohen et al., 2013; Dempsey et al., 2015; Marshel et al., 2010).

Since the molecular weights of plasmids are several folds larger than morphological tracers, the easiest way to deliver them into cells is with whole-cell approaches. However, juxtacellular and loose-patch approaches can be also used provided large pores are opened into the membrane. Successful transfection has been also reported using semisharp pipettes (Dempsey et al., 2015).

Electroporating plasmids through the cellular membrane requires using large voltage steps ( $>10 \mathrm{~V}$ ), which for a pipette of $15 \mathrm{M} \Omega$ means passing currents larger than 600 nA (Haas et al., 2001; Judkewitz et al., 2009; Marshel et al., 2010). This is not possible with most conventional intracellular amplifiers. While there are commercial alternatives, a solution is using a relay to interface between the amplifier and a pulse generator so that it can switch from the recording to the electroporating mode (Cohen et al., 2013).

Before use, plasmids are amplified, purified, filtered and stored in double-distilled water. The final plasmid concentration is around $200 \mathrm{ng} / \mu \mathrm{l}$ regardless the approach.

Repetitive negative pulses of $2-20 \mathrm{~V}$ are required for juxtacellular and loose- or cell-attached patch recordings. The protocol in particular may depend on the cell-type and the region of interest and should be empirically adjusted. Basically, it consists of short pulses (0.1-0.5 ms) repeated at $50 \mathrm{~Hz}$ or $1000 \mathrm{~Hz}$ during short periods of time $(1 \mathrm{~s})$. Some researchers recommend establishing a short intracellular access before electroporation to increase the chances of transfection (Dempsey et al., 2015).

After electroporating with large currents, neurons will become transitorily active. Stay in place for a while and then remove the pipette from the cell and recover the animal.

DNA plasmids are usually electroporated guided by two-photon imaging and combined with morphological fluorescent dyes as Alexa (at $50 \mu \mathrm{M}$ ) to help in targeting cells (Cohen et al., 2013; Judkewitz et al., 2009; Kitamura et al., 2008; Marshel et al., 2010). When doing blindly, an inconvenience is that it is not possible to determine if the labelling attempt was successful until processing the brain sections. Contrary to juxtacellular labelling which gives immediate feedback by cell firing modulation, electroporation of DNA is often disruptive.

\section{Cell-type specific identification}

Cells are typically submitted to different protocols in order to define their identity with neurochemical and/or morphological analysis. After having cut the brain in sections with a vibratome (typically $50-70 \mu \mathrm{m}$ ), the cell has to be localized. This is a difficult task since there are many potential sections containing the soma, dendrites and axonal arborizations. At some instances, recording sites can be identified by dye spillover at the cortex over the recording site or by identifying traces of a pipette tract. When plasmids are incorporated constitutively to the recorded cell, their localization is more straightforward. However, for Neurobiotin or biocytin, chemical reactions are required for visualization. Using streptavidin-conjugated fluorophores allows for subsequent multiplexed neurochemical analysis by co-localization with cell-type specific markers. For instance, sections containing the soma can be used to test a battery of antibodies with cytosolic expression, while sections containing the dendrites may help in adding other specific markers (Salib et al., 2019; Viney et al., 2018). After having completed immunofluorescence analysis, the avidin-biotin-peroxidase reaction can be used to visualize the entire morphology of the cell. This technique is much more sensitive and therefore highly recommended, especially to visualize axon. Protocols for either the avidin-biotin-peroxidase reaction or streptavidin-conjugated immunofluorescence are reported elsewhere (Butler et al., 2019; Morozov et al., 2002). They can also be adapted for electron microscopy by avoiding detergents like Triton and using freeze-thaw to permeabilize membranes. (Joshi et al., 2017; Lapray et al., 2012; Lau et al., 2017; Massi et al., 2012; Takács et al., 2012; Tukker et al., 2013; Viney et al., 2013). More recently, applying tissue clearing methods may help in reconstructing brain-wide projections of single-cells filled with fluorescent dyes or reporter plasmids (Lin et al., 2018).

For each brain region of interest, different cell-types are being classified according to morphology, location and specific expression of different proteins. For instance, in the CA1 region of the hippocampus, more than 25 types of interneurons and at least 3 types of pyramidal cells have been described after neurochemical characterization (Gulyás et al., 1998; Harris et al., 2018; Wheeler et al., 2015). When complemented with the functional characterization of activity patterns during hippocampal oscillations, our ability to classify different celltypes unfolds considerably (Klausberger and Somogyi, 2008; Valero et al., 2015).

We recommend using decision trees to plan for functional, neurochemical and morphological identification of the different cell-types in a given region. Here we provide a generic framework that can be easily adapted depending on the region and cell type of interest (Fig. 4). For instance, while targeting regions of very well-known neurochemical cell-types, priority can be given to markers. In contrast, for unknown cell-types in a region, it may be recommended to prioritize morphological analysis, such as axonal or dendritic specializations.

1) Adopt a preliminary functional description of cell activity in general terms such as interneurons versus pyramidal or any other particular subtype based on physiological information (Fig. 4A).

2) Localize sections containing the cell soma and dendrites and proceed with morphological analysis (Fig. 4B).

3) Check for the location of the cell soma within different subregions and layers.

4) Check for the shape, size and orientation of the soma.

5) Check for dendritic morphological features, such as polarity of the dendritic arbor, the presence of spines or any other specialization that may help to reduce the range of possible cell types.

6) Check for axonal features such as the origin, bifurcations and the presence of local boutons.

7) Make hypothesis on the potential cell-type based on morphological and physiological information (Fig. 4C) and select the proteins to be tested by immunohistochemistry (Fig. 4D). Different cell 


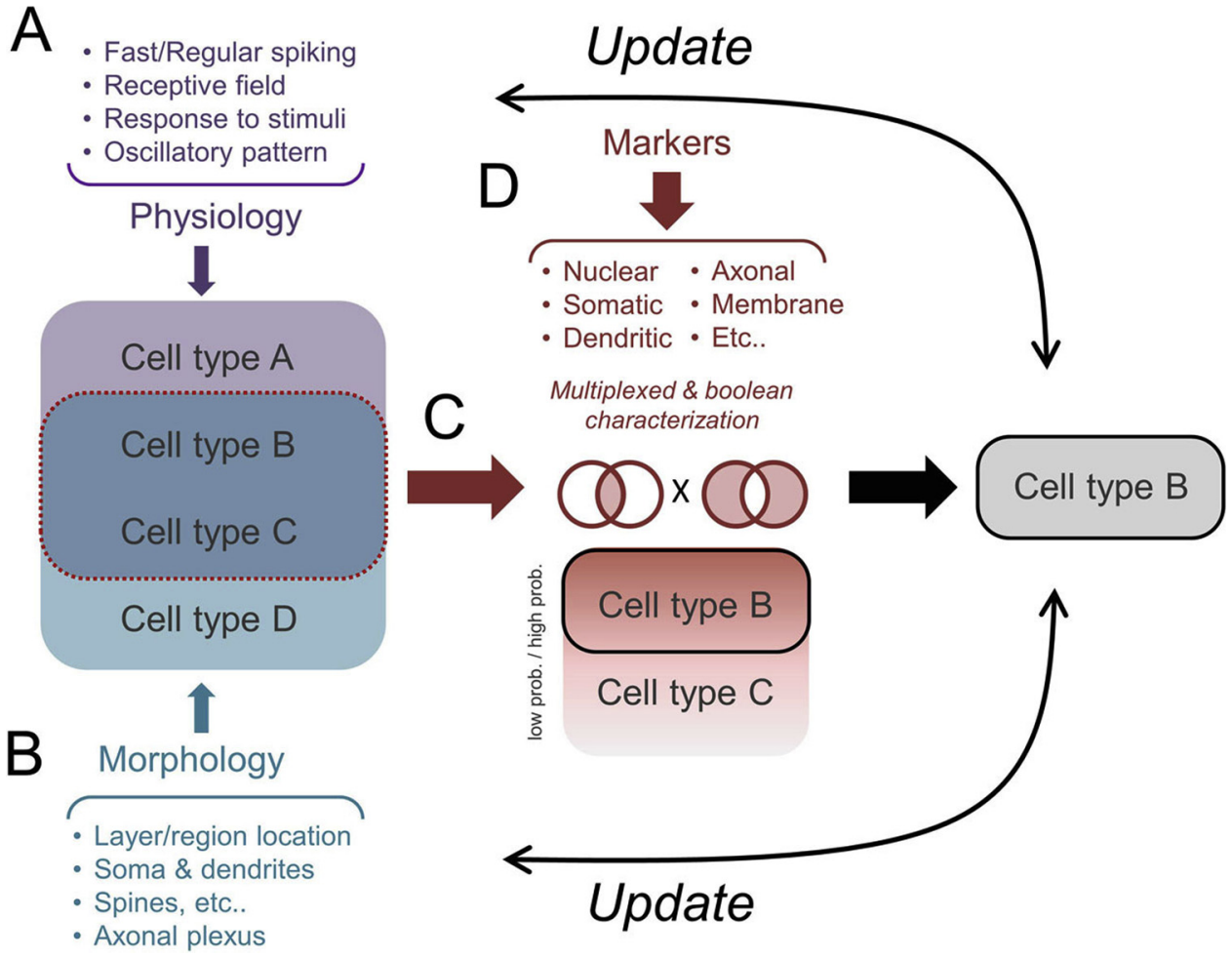

Fig. 4. Generic flowchart to characterize single-cell identity by exploiting physiological, morphological and neurochemical profiling.

compartments (soma, dendrites, nucleus, cytoplasm, membrane) can be exploited to increase the number of complementary antibodies. Consider using several rounds of immunolabeling starting with the "most likely negative" antibody first and the "most likely positive" afterwards.

8) Finally, reconstruction of cell morphology (dendritic and axonal arborization) after avidin-biotin-peroxidase reaction will provide additional data, primarily on the axonal plexus, which sometimes is critical to distinguish between cell types. This step can be also made in advance in some sections since provides information that help in deciding what to test.

\section{Emerging technological approaches}

In spite of recent advances in high-throughput methods for singlecell studies, there is no new technique allowing for massively targeting single-cells for electrophysiological and morphological characterization in vivo. However, some emerging approaches are challenging the experimental paradigms to a point that new alternatives may emerge in forthcoming years.

With the irruption of promoter-specific transgenic strategies, some cellular subpopulations can be assessed, but at the expenses of accepting their intrinsic heterogeneity. For example, PV-Cre mice are available to target PV-positive interneurons that in the hippocampus can comprise a subset of basket cells, but also axo-axonic cells, bistratified cells and some oriens-alveus interneurons (Klausberger and Somogyi, 2008). Using novel intersectional approaches, the role of some of these subpopulations could be further separated with optogenetic and/or functional imaging such as GCaMP (Fenno et al., 2014). Perhaps a very promising tool is using genetically encoded voltage indicators, which allow for multi-cellular recording of membrane potential fluctuations and spikes (Peterka et al., 2011; Xu et al., 2017). While poor signal-to-noise ratio and photobleaching of these probes still remains an issue (Bando et al., 2019), recent advances are promising (Adam et al., 2019). More recently, optical tools are being developed to label active neurons in vivo by exploiting engineered calcium integrators such as CaMPARI (Fosque et al., 2015). Yet, identifying individual activities of all these cells and relating them with their transcriptional and/or neurochemical identity is not feasible.

New techniques now integrate different functionalities in individual glass pipettes to expand the toolbox of methods, including optogenetics, pharmacology or electrochemistry, that can be applied for single-cell analysis (Hunt et al., 2019; Katz et al., 2013; Packer et al., 2015; see also Katz et al., 2019). Collecting different samples of individual celltypes in vivo is time consuming though, which intrinsically limits the application of the technique. Strikingly, many of the protocol steps described above can be robotized and automatic patcher are now available to speed up recordings (Suk et al., 2019). These robots can be combined together to gain in multi-patching abilities (Kodandaramaiah et al., 2018). Just recently, flexible nanopipettes allowed for simultaneous recordings of pairs of neurons or of different compartments within single-cells (Jayant et al., 2019).

So far, using glass pipettes remains unbeatable in their ability to relate the physiology and anatomy of single-cells in vivo. This review summarized the most important steps to facilitate revitalizing the method in the era of single-cell omics. However, if we want to take a leap forward in our ability to characterize single-cells precisely we should certainly keep challenging the approach.

\section{Acknowledgements}

We thank Alberto Sanchez-Aguilera, Manuel Valero and Robert Averkin for their useful comments. We also thank the two anonymous reviewers for feedback and suggestions. Our work on single-cell studies was supported by grants from the Spanish Government (BFU201237156-C03-01 and BFU2015-66887-R) and the Fundación Tatiana Pérez de Guzman el Bueno.

\section{Appendix A. Supplementary data}

Supplementary material related to this article can be found, in the online version, at doi:https://doi.org/10.1016/j.jneumeth.2019. 
108354.

\section{References}

Adam, Y., Kim, J.J., Lou, S., Zhao, Y., Xie, M.E., Brinks, D., Wu, H., Mostajo-Radji, M.A., Kheifets, S., Parot, V., Chettih, S., Williams, K.J., Gmeiner, B., Farhi, S.L., Madisen, L., Buchanan, E.K., Kinsella, I., Zhou, D., Paninski, L., Harvey, C.D., Zeng, H., Arlotta, P., Campbell, R.E., Cohen, A.E., 2019. Voltage imaging and optogenetics reveal behaviour-dependent changes in hippocampal dynamics. Nature 569, 413-417. https:// doi.org/10.1038/s41586-019-1166-7.

Anderson, J.C., Martin, K.A.C., Whitteridge, D., 1993. Form, function, and intracortical projections of neurons in the striate cortex of the monkey Macacus nemestrinus. Cereb. Cortex 3, 412-420. https://doi.org/10.1093/cercor/3.5.412.

Arszovszki, A., Borhegyi, Z., Klausberger, T., 2014. Three axonal projection routes of individual pyramidal cells in the ventral CA1 hippocampus. Front. Neuroanat. 8 , 1-11. https://doi.org/10.3389/fnana.2014.00053.

Averkin, R.G., Szemenyei, V., Bordé, S., Tamás, G., 2016. Identified cellular correlates of neocortical ripple and high-gamma oscillations during spindles of natural sleep. Neuron 92, 916-928. https://doi.org/10.1016/j.neuron.2016.09.032.

Bando, Y., Sakamoto, M., Kim, S., Ayzenshtat, I., Yuste, R., 2019. Comparative evaluation of genetically encoded voltage indicators. Cell Rep. 26, 802-813. https://doi.org/10. 1016/J.CELREP.2018.12.088, e4.

Borhegyi, Z., Varga, V., Szilagyi, N., Fabo, D., Freund, T.F., 2004. Phase segregation of medial septal GABAergic neurons during hippocampal Theta activity. J. Neurosci. 24, 8470-8479. https://doi.org/10.1523/jneurosci.1413-04.2004.

Brecht, M., Sakmann, B., 2002. Whisker maps of neuronal subclasses of the rat ventral posterior medial thalamus, identified by whole-cell voltage recording and morphological reconstruction. J. Physiol. 538, 495-515. https://doi.org/10.1113/jphysiol. 2001.012334.

Bretag, A., 1983. Who did invent the intracellular microelectrode? Trends Neurosci. 6, 365. https://doi.org/10.1016/0166-2236(83)90165-0.

Brette, R., Destexhe, A., 2012. Intracellular recording. In: Brette, R., Destexhe, A. (Eds.), Handbook of Neural Activity Measurement. Cambridge University Press, Paris, pp. 44-91. https://doi.org/10.1017/CBO9780511979958.003.

Brown, M.T.C., Henny, P., Bolam, J.P., Magill, P.J., 2009. Activity of neurochemically heterogeneous dopaminergic neurons in the Substantia Nigra during spontaneous and driven changes in brain state. J. Neurosci. 29, 2915-2925. https://doi.org/10.1523/ jneurosci.4423-08.2009.

Burgalossi, A., Herfst, L., von Heimendahl, M., Förste, H., Haskic, K., Schmidt, M., Brecht, M., 2011. Microcircuits of functionally identified neurons in the rat medial entorhinal cortex. Neuron 70, 773-786. https://doi.org/10.1016/j.neuron.2011.04.003.

Butler, J.L., Barham, B.J., Heidenreich, B.A., 2019. Comparison of indirect peroxidase and avidin-biotin-peroxidase complex (ABC) immunohistochemical staining procedures for c-fos in rat brain. J. Anat. 234, 936-942. https://doi.org/10.1111/joa.12967.

Cembrowski, M.S., 2019. Single-cell Transcriptomics as a Framework and Roadmap for Understanding the Brain. This issue.

Cohen, J.D., Bolstad, M., Lee, A.K., 2017. Experience-dependent shaping of hippocampal CA1 intracellular activity in novel and familiar environments. Elife 6https://doi.org/ 10.7554/eLife.23040. pii: e23040.

Cohen, L., Koffman, N., Meiri, H., Yarom, Y., Lampl, I., Mizrahi, A., 2013. Time-lapse electrical recordings of single neurons from the mouse neocortex. Proc. Natl. Acad. Sci. 110, 5665-5670. https://doi.org/10.1073/pnas.1214434110.

Coletta, S., Zeraati, R., Nasr, K., Preston-Ferrer, P., Burgalossi, A., 2018. Interspike interval analysis and spikelets in presubicular head-direction cells. J. Neurophysiol. 120, 564-575. https://doi.org/10.1152/jn.00019.2018.

Contreras, D., Steriade, M., 1995. Cellular basis of EEG slow rhythms: a study of dynamic corticothalamic relationships. J. Neurosci. 15, 604-622. https://doi.org/10.1523/ jneurosci.15-01-00604.1995.

Crochet, S., Petersen, C.C.H., 2006. Correlating whisker behavior with membrane potential in barrel cortex of awake mice. Nat. Neurosci. 9, 608-610. https://doi.org/10. 1038/nn1690.

de Kock, C.P.J., Sakmann, B., 2009. Spiking in primary somatosensory cortex during natural whisking in awake head-restrained rats is cell-type specific. Proc. Natl. Acad. Sci. 106, 16446-16450. https://doi.org/10.1073/pnas.0904143106.

Dempsey, B., Turner, A.J., Le, S., Sun, Q.-J., Farah, L.B., Allen, A.M., Goodchild, A.K., McMullan, S., 2015. Recording, labeling, and transfection of single neurons in deep brain structures. Physiol. Rep. 3https://doi.org/10.14814/phy2.12246. pii: e12246.

Diamantaki, M., Coletta, S., Nasr, K., Zeraati, R., Laturnus, S., Berens, P., Preston-Ferrer, P., Burgalossi, A., 2018. Manipulating hippocampal place cell activity by single-cell stimulation in freely moving mice. Cell Rep. 23, 32-38. https://doi.org/10.1016/j. celrep.2018.03.031.

Duque, A., Zaborszky, L., 2006. Juxtacellular Labeling of Individual Neurons In Vivo: From Electrophysiology to Synaptology. In: Zaborszky, L., Wouterlood, F.G., L.J (Eds.), Neuroanatomical Tract-Tracing 3: Molecules, Neurons, and Systems. Springer, New York, pp. 197-236. https://doi.org/10.1007/0-387-28942-9.

English, D.F., Peyrache, A., Stark, E., Roux, L., Vallentin, D., Long, M.A., Buzsáki, G., 2014. Excitation and inhibition compete to control spiking during hippocampal ripples: intracellular study in behaving mice. J. Neurosci. 34, 16509-16517. https:// doi.org/10.1523/jneurosci.2600-14.2014.

Epsztein, J., Brecht, M., Lee, A.K., 2011. Intracellular determinants of hippocampal CA1 place and silent cell activity in a novel environment. Neuron 70, 109-120. https:// doi.org/10.1016/j.neuron.2011.03.006.

Fee, M.S., 2000. Active stabilization of electrodes for intracellular recording in awake behaving animals. Neuron 27, 461-468. https://doi.org/10.1016/S0896-6273(00) 00057-X.
Fenno, L.E., Mattis, J., Ramakrishnan, C., Hyun, M., Lee, S.Y., He, M., Tucciarone, J., Selimbeyoglu, A., Berndt, A., Grosenick, L., Zalocusky, K.A., Bernstein, H., Swanson, H., Perry, C., Diester, I., Boyce, F.M., Bass, C.E., Neve, R., Huang, Z.J., Deisseroth, K., 2014. INTRSECT: single-component targeting of cells using multiple- feature Boolean logic. Nat. Methods 11, 763-772. https://doi.org/10.1038/nmeth.2996.

Fernandez-Lamo, I., Gomez-Dominguez, D., Sanchez-Aguilera, A., Oliva, A., Morales, A.V., Valero, M., Cid, E., Berenyi, A., Menendez de la Prida, L., 2019. Proximodistal organization of the CA2 hippocampal area. Cell Rep. 26, 1734-1746. https://doi.org/ 10.1016/j.celrep.2019.01.060. e6.

Fosque, B.F., Sun, Y., Dana, H., Yang, C.-T., Ohyama, T., Tadross, M.R., Patel, R., Zlatic, M., Kim, D.S., Ahrens, M.B., Jayaraman, V., Looger, L.L., Schreiter, E.R., 2015. Neura circuits. Labeling of active neural circuits in vivo with designed calcium integrators. Science 347, 755-760. https://doi.org/10.1126/science.1260922.

Friedlander, M.J., Lin, C.S., Sherman, S.M., 1979. Structure of physiologically identified X and Y cells in the cat's lateral geniculate nucleus. Science 204, 1114-1117. https:// doi.org/10.1126/science.451559.

Gulyás, A.I., Tóth, K., McBain, C.J., Freund, T.F., 1998. Stratum radiatum giant cells: a type of principal cell in the rat hippocampus. Eur. J. Neurosci. 10, 3813-3822. https://doi.org/10.1046/j.1460-9568.1998.00402.x.

Haas, K., Sin, W.-C., Javaherian, A., Li, Z., Cline, H.T., 2001. Single-cell electroporation neurotechnique for gene transfer in vivo. Neuron 29, 583-591. https://doi.org/10. 1016/S0896-6273(01)00235-5.

Harris, K.D., Hochgerner, H., Skene, N.G., Magno, L., Katona, L., Bengtsson Gonzales, C., Somogyi, P., Kessaris, N., Linnarsson, S., Hjerling-Leffler, J., 2018. Classes and continua of hippocampal CA1 inhibitory neurons revealed by single-cell transcriptomics. PLoS Biol. 16. https://doi.org/10.1371/journal.pbio.2006387.

Harvey, C.D., Collman, F., Dombeck, D.A., Tank, D.W., 2009. Intracellular dynamics of hippocampal place cells during virtual navigation. Nature 461, 941-946. https://doi. org/10.1038/nature08499.

Herfst, L., Burgalossi, A., Haskic, K., Tukker, J.J., Schmidt, M., Brecht, M., 2012. Frictionbased stabilization of juxtacellular recordings in freely moving rats. J. Neurophysiol. 108, 697-707. https://doi.org/10.1152/jn.00910.2011.

Houweling, A.R., Brecht, M., 2008. Behavioural report of single neuron stimulation in somatosensory cortex. Nature 451, 65-68. https://doi.org/10.1038/nature06447.

Houweling, A.R., Doron, G., Voigt, B.C., Herfst, L.J., Brecht, M., 2010. Nanostimulation: manipulation of single neuron activity by juxtacellular current injection. J. Neurophysiol. 103, 1696-1704. https://doi.org/10.1152/jn.00421.2009.

Hulse, B.K., Moreaux, L.C., Lubenov, E.V., Siapas, A.G., 2016a. Membrane potential dynamics of CA1 pyramidal neurons during hippocampal ripples in awake mice. Neuron 89, 800-813. https://doi.org/10.1016/j.neuron.2016.01.014.

Hulse, B.K., Moreaux, L.C., Lubenov, E.V., Siapas, A.G., 2016b. Membrane potential dynamics of CA1 pyramidal neurons during hippocampal ripples in awake mice. Neuron 89, 800-813. https://doi.org/10.1002/jmri.25711.PET/MRI

Hunt, D.L., Lai, C., Smith, R.D., Lee, A.K., Harris, T.D., Barbic, M., 2019. Multimodal in vivo brain electrophysiology with integrated glass microelectrodes. Nat. Biomed. Eng. https://doi.org/10.1038/s41551-019-0373-8.

Jayant, K., Wenzel, M., Bando, Y., Hamm, J.P., Mandriota, N., Rabinowitz, J.H., Plante, I.J.-L., Owen, J.S., Sahin, O., Shepard, K.L., Yuste, R., 2019. Flexible nanopipettes for minimally invasive intracellular electrophysiology in vivo. Cell Rep. 26, 266-278. https://doi.org/10.1016/j.celrep.2018.12.019. e5.

Joshi, A., Salib, M., Viney, T.J., Dupret, D., Somogyi, P., 2017. Behavior-dependent activity and synaptic organization of septo-hippocampal gabaergic neurons selectively targeting the hippocampal CA3 area. Neuron 96, 1342-1357. https://doi.org/10. 1016/J.NEURON.2017.10.033. e5.

Joshi, S., Hawken, M.J., 2006. Loose-patch-juxtacellular recording in vivo-a method for functional characterization and labeling of neurons in macaque V1. J. Neurosci. Methods 156, 37-49. https://doi.org/10.1016/J.JNEUMETH.2006.02.004.

Jouhanneau, J.-S., Poulet, J.F.A., 2019. Multiple two-photon targeted whole-cell patchclamp recordings from monosynaptically connected neurons in vivo. Front. Synaptic Neurosci. 11, 1-13. https://doi.org/10.3389/fnsyn.2019.00015.

Judkewitz, B., Rizzi, M., Kitamura, K., Häusser, M., 2009. Targeted single-cell electroporation of mammalian neurons in vivo. Nat. Protoc. 4, 862-869. https://doi.org/10. 1038/nprot.2009.56.

Kamondi, A., Acsády, L., Buzsáki, G., 1998. Dendritic spikes are enhanced by cooperative network activity in the intact Hippocampus. J. Neurosci. 18, 3919-3928. https://doi. org/10.1523/jneurosci.18-10-03919.1998.

Katona, L., Micklem, B., Borhegyi, Z., Swiejkowski, D.A., Valenti, O., Viney, T.J., Kotzadimitriou, D., Klausberger, T., Somogyi, P., 2017. Behavior-dependent activity patterns of GABAergic long-range projecting neurons in the rat hippocampus. Hippocampus 27, 359-377. https://doi.org/10.1002/hipo.22696.

Katz, Y., Sokoletsky, M., Lampl, I., 2019. In-Vivo Optogenetics and Pharmacology in Deep Intracellular Recordings. This issue.

Katz, Y., Yizhar, O., Staiger, J., Lampl, I., 2013. Optopatcher-an electrode holder for simultaneous intracellular patch-clamp recording and optical manipulation. J. Neurosci. Methods 214, 113-117. https://doi.org/10.1016/j.jneumeth.2013.01.017.

Kelly, J.P., Van Essen, D.C., 1974. Cell structure and function in the visual cortex of the cat. J. Physiol. 238, 515-547. https://doi.org/10.1113/jphysiol.1974.sp010541.

Kita, H., Armstrong, W., 1991. A biotin-containing compound N-(2-aminoethyl)biotinamide for intracellular labeling and neuronal tracing studies: comparison with biocytin. J. Neurosci. Methods 37, 141-150. https://doi.org/10.1016/0165-0270(91) 90124-I.

Kitai, S.T., Kocsis, J.D., Preston, R.J., Sugimori, M., 1976. Monosynaptic inputs to caudate neurons identified by intracellular injection of horseradish peroxidase. Brain Res. 109, 601-606. https://doi.org/10.1016/0006-8993(76)90039-1.

Kitamura, K., Judkewitz, B., Kano, M., Denk, W., Häusser, M., 2008. Targeted patchclamp recordings and single-cell electroporation of unlabeled neurons in vivo. Nat. 
Methods 5, 61-67. https://doi.org/10.1038/nmeth1150.

Klausberger, T., Magill, P.J., Márton, L.F., Roberts, J.D.B., Cobden, P.M., Buzsáki, G., Somogyi, P., 2003. Brain-state- and cell-type-specific firing of hippocampal interneurons in vivo. Nature 421, 844-848. https://doi.org/10.1038/nature01374.

Klausberger, T., Somogyi, P., 2008. Neuronal diversity and temporal dynamics: the unity of hippocampal circuit operations. Science 321, 53-57. https://doi.org/10.1126/ science. 1149381

Kodandaramaiah, S.B., Flores, F.J., Holst, G.L., Singer, A.C., Han, X., Brown, E.N., Boyden, E.S., Forest, C.R., 2018. Multi-neuron intracellular recording in vivo via interacting autopatching robots. Elife 7. https://doi.org/10.7554/eLife.24656.

Konopacki, J., Bland, B.H., Dyck, R., 2003. Intracellular recording and labeling of neurons in midline structures of the rat brain in vivo using sharp electrodes. J. Neurosci. Methods 127, 85-93. https://doi.org/10.1016/S0165-0270(03)00126-2.

Korshunov, V.A., 2006. Miniature microdrive-headstage assembly for extracellular recording of neuronal activity with high-impedance electrodes in freely moving mice. J. Neurosci. Methods 158, 179-185. https://doi.org/10.1016/J.JNEUMETH.2006.05. 031.

Lapray, D., Lasztoczi, B., Lagler, M., James Viney, T., Katona, L., Valenti, O., Hartwich, K., Borhegyi, Z., Somogyi, P., Klausberger, T., 2012. Behavior-dependent specialization of identified hippocampal interneurons. Nat. Neurosci. 15, 1265-1271. https://doi. org/10.1038/nn.3176.

Lau, P.Y.P., Katona, L., Saghy, P., Newton, K., Somogyi, P., Lamsa, K.P., 2017. Long-term plasticity in identified hippocampal GABAergic interneurons in the CA1 area in vivo. Brain Struct. Funct. 222, 1809-1827. https://doi.org/10.1007/s00429-016-1309-7.

Lee, A.K., Brecht, M., 2018. Elucidating neuronal mechanisms using intracellular recordings during behavior. Trends Neurosci. 41, 385-403. https://doi.org/10.1016/j. tins.2018.03.014.

Lee, A.K., Epsztein, J., Brecht, M., 2009. Head-anchored whole-cell recordings in freely moving rats. Nat. Protoc. 4, 385-392. https://doi.org/10.1038/nprot.2009.5.

Lee, A.K., Manns, I.D., Sakmann, B., Brecht, M., 2006. Whole-cell recordings in freely moving rats. Neuron 51, 399-407. https://doi.org/10.1016/j.neuron.2006.07.004.

Li, X.-G., Somogyi, P., Tepper, J.M., Buzsáki, G., 1992. Axonal and dendritic arborization of an intracellularly labeled chandelier cell in the CA1 region of rat hippocampus. Exp. Brain Res. 90, 519-525. https://doi.org/10.1007/BF00230934.

Li, X.-G., Somogyi, P., Ylinen, A., Buzsaki, G., 1994. The hippocampal CA3 network: an in vivo intracellular labeling study. J. Comp. Neurol. 339, 181-208. https://doi.org/10. 1002/cne.903390204.

Lin, C., Friedlander, M.J., Sherman, S.M., 1979. Morphology of physiologically identified neurons in the visual cortex of the cat. Brain Res. 172, 344-348.

Lin, R., Wang, R., Yuan, J., Feng, Q., Zhou, Y., Zeng, S., Ren, M., Jiang, S., Ni, H., Zhou, C., Gong, H., Luo, M., 2018. Cell-type-specific and projection-specific brain-wide reconstruction of single neurons. Nat. Methods 15, 1033-1036. https://doi.org/10. 1038/s41592-018-0184-y.

Ling, G., Gerard, R.W., 1949. The normal membrane potential of frog sartorius fibers. J. Cell. Comp. Physiol. 34, 383-396. https://doi.org/10.1002/jcp.1030340304.

Liu, L., Duff, K., 2008. A technique for serial collection of cerebrospinal fluid from the Cisterna Magna in mouse. J. Vis. Exp. 960. https://doi.org/10.3791/960.

Long, M.A., Jin, D.Z., Fee, M.S., 2010. Support for a synaptic chain model of neuronal sequence generation. Nature 468, 394-399. https://doi.org/10.1038/nature09514.

Long, M.A., Lee, A.K., 2012. Intracellular recording in behaving animals. Curr. Opin. Neurobiol. 22, 34-44. https://doi.org/10.1016/j.conb.2011.10.013.

Maier, N., Tejero-Cantero, Á., Dorrn, A.L., Winterer, J., Beed, P.S., Morris, G., Kempter R., Poulet, J.F.A., Leibold, C., Schmitz, D., 2011. Coherent phasic excitation during hippocampal ripples. Neuron 72, 137-152. https://doi.org/10.1016/j.neuron.2011. 08.016.

Margrie, T.W., Brecht, M., Sakmann, B., 2002. In vivo, low-resistance, whole-cell recordings from neurons in the anaesthetized and awake mammalian brain. Pflugers Arch. Eur. J. Physiol. 444, 491-498. https://doi.org/10.1007/s00424-002-0831-z.

Marshel, J.H., Mori, T., Nielsen, K.J., Callaway, E.M., 2010. Targeting single neuronal networks. Neuron 67, 562-574. https://doi.org/10.1016/j.neuron.2010.08.001. Targeting.

Martin, K.A.C., Whitteridge, D., 1984. Form, function and intracortical projections of spiny neurones in the striate visual cortex of the cat. J. Physiol. 353, 463-504. https://doi.org/10.1113/jphysiol.1984.sp015347.

Massi, L., Lagler, M., Hartwich, K., Borhegyi, Z., Somogyi, P., Klausberger, T., 2012. Temporal dynamics of parvalbumin-expressing axo-axonic and basket cells in the rat medial prefrontal cortex in vivo. J. Neurosci. 32, 16496-16502. https://doi.org/10. 1523/jneurosci.3475-12.2012.

Menendez de la Prida, L., Suarez, F., Pozo, M.A., 2002. The effect of different morphological sampling criteria on the fraction of bursting cells recorded in the rat subiculum in vitro. Neurosci. Lett. 322, 49-52. https://doi.org/10.1016/S03043940(02)00085-X.

Moore, J.D., Deschênes, M., Kleinfeld, D., 2015. Juxtacellular monitoring and localization of single neurons within sub-cortical brain structures of alert, head-restrained rats. J. Vis. Exp. https://doi.org/10.3791/51453.

Morozov, Y., Khalilov, I., Ben-Ari, Y., Represa, A., 2002. Correlative fluorescence and electron microscopy of biocytin-filled neurons with a preservation of the postsynaptic ultrastructure. J. Neurosci. Methods 117, 81-85. https://doi.org/10.1016/S0165 0270(02)00076-6.

Narayanan, R.T., Mohan, H., Broersen, R., de Haan, R., Pieneman, A.W., de Kock, C.P.J., 2014. Juxtasomal biocytin labeling to study the structure-function relationship of individual cortical neurons. J. Vis. Exp. https://doi.org/10.3791/51359.

Nevian, T., Helmchen, F., 2007. Calcium indicator loading of neurons using single-cell electroporation. Pflugers Arch. Eur. J. Physiol. 454, 675-688. https://doi.org/10 1007/s00424-007-0234-2.

Núñez, A., García-Austt, E., Buño, W., 1987. Intracellular $\theta$-rhythm generation in identified hippocampal pyramids. Brain Res. 416, 289-300. https://doi.org/10. 1016/0006-8993(87)90909-7.

Oberlaender, M., Ramirez, A., Bruno, R.M., 2012. Sensory experience restructures thalamocortical axons during adulthood. Neuron 74, 648-655. https://doi.org/10.1016/ j.neuron.2012.03.022.

Oesterle, A., 2018. Pipette Cookbook 2018 P-97 \& P-1000 Micropipette Pullers. Sutter Instrument Companyhttps://doi.org/10.1002/ejoc.201200111.

Oyama, K., Ohara, S., Sato, S., Karube, F., Fujiyama, F., Isomura, Y., Mushiake, H., Iijima T., Tsutsui, K.I., 2013. Long-lasting single-neuron labeling by in vivo electroporation without microscopic guidance. J. Neurosci. Methods 218, 139-147. https://doi.org/ 10.1016/j.jneumeth.2013.06.004.

Packer, A.M., Russell, L.E., Dalgleish, H.W.P., Häusser, M., 2015. Simultaneous all-optical manipulation and recording of neural circuit activity with cellular resolution in vivo. Nat. Methods 12, 140-146. https://doi.org/10.1038/nmeth.3217.

Pager, J., 1984. A removable head-mounted microdrive for unit recording in the freebehaving rat. Physiol. Behav. 33, 843-848. https://doi.org/10.1016/0031-9384(84) 90057-X.

Peterka, D.S., Takahashi, H., Yuste, R., 2011. Imaging voltage in neurons. Neuron 69, 9-21. https://doi.org/10.1016/j.neuron.2010.12.010.

Pinault, D., 1996. A novel single-cell staining procedure performed in vivo under electrophysiological control: morpho-functional features of juxtacellularly labeled thalamic cells and other central neurons with biocytin or Neurobiotin. J. Neurosci. Methods 65, 113-136. https://doi.org/10.1016/0165-0270(95)00144-1.

Polack, P.-O., Friedman, J., Golshani, P., 2013. Cellular mechanisms of brain-state-dependent gain modulation in visual cortex. Nat. Neurosci. 16, 1331-1339. https://doi. org/10.1038/nn.3464.

Poulet, J.F.A., Petersen, C.C.H., 2008. Internal brain state regulates membrane potential synchrony in barrel cortex of behaving mice. Nature 454, 881-885. https://doi.org/ 10.1038/nature07150.

Preston-Ferrer, P., Burgalossi, A., 2018. Linking neuronal structure to function in rodent hippocampus: a methodological prospective. Cell Tissue Res. 373, 605-618. https:// doi.org/10.1007/s00441-017-2732-7.

Quilichini, P., Sirota, A., Buzsaki, G., 2010. Intrinsic circuit organization and thetagamma oscillation dynamics in the entorhinal cortex of the rat. J. Neurosci. 30, 11128-11142. https://doi.org/10.1523/jneurosci.1327-10.2010.

Rancz, E.A., Franks, K.M., Schwarz, M.K., Pichler, B., Schaefer, A.T., Margrie, T.W., 2011 Transfection via whole-cell recording in vivo: bridging single-cell physiology, genetics and connectomics. Nat. Neurosci. 14, 527-532. https://doi.org/10.1038/nn. 2765 .

Salib, M., Joshi, A., Katona, L., Howarth, M., Micklem, B., Somogyi, P., Viney, T.J., 2019 GABAergic medial septal neurons with low-rhythmic firing innervating the dentate gyrus and hippocampal area CA3. J. Neurosci. https://doi.org/10.1523/JNEUROSCI. 3024-18.2019. 3024-18.

Schwarz, M.K., Remy, S., 2019. Rabies Virus-Mediated Connectivity Tracing from Single Neurons. This issue.

Sik, A., Penttonen, M., Ylinen, A., Buzsáki, G., 1995. Hippocampal CA1 interneurons: an in vivo intracellular labeling study. J. Neurosci. 15, 6651-6665. https://doi.org/10. 1523/JNEUROSCI.15-10-06651.1995.

Somogyi, P., 1988. Immunocytochemical demonstration of GABA in physiologically characterized, HRP-filled neurons and their postsynaptic targets. In: Van Leewen, F., Buijs, R., Pool, C., Pach, O. (Eds.), Molecular Neuroanatomy. Elsevier Science Publishers B. V. (Biomedical Division), Amsterdam, pp. 339-359.

Somogyi, P., Kisvárday, Z.F., Martin, K.A.C., Whitteridge, D., 1983. Synaptic connections of morphologically identified and physiologically characterized large basket cells in the striate cortex of cat. Neuroscience 10, 261-294. https://doi.org/10.1016/03064522(83)90133-1.

Spruston, N., Jaffe, D.B., Williams, S.H., Johnston, D., 1993. Voltage- and space-clamp errors associated with the measurement of electrotonically remote synaptic events. J. Neurophysiol. 70, 781-802. https://doi.org/10.1152/jn.1993.70.2.781.

Steriade, M., Nuñez, A., Amzica, F., 1993a. A novel slow $(<1 \mathrm{~Hz})$ oscillation of neocortical neurons in vivo: depolarizing and hyperpolarizing components. J. Neurosci. 13, 3252-3265. https://doi.org/10.1523/JNEUROSCI.13-08-03252.1993.

Steriade, M., McCormick, D.A., Sejnowski, T.J., 1993b. Thalamocortical oscillations in the sleeping and aroused brain. Science 262, 679-685. https://doi.org/10.1126/science. 8235588.

Steriade, M., Timofeev, I., Grenier, F., 2001. Natural waking and sleep states: a view from inside neocortical neurons. J. Neurophysiol. 85, 1969-1985. https://doi.org/10. 1152/jn.2001.85.5.1969.

Suk, H., Boyden, E.S., van Welie, I., 2019. Advances in Automation of Whole-Cell Patch Clamp Technology. This issue.

Takács, V.T., Klausberger, T., Somogyi, P., Freund, T.F., Gulyás, A.I., 2012. Extrinsic and local glutamatergic inputs of the rat hippocampal CA1 area differentially innervate pyramidal cells and interneurons. Hippocampus 22, 1379-1391. https://doi.org/10. 1002/hipo.20974.

Tang, Q., Brecht, M., Burgalossi, A., 2014. Juxtacellular recording and morphological identification of single neurons in freely moving rats. Nat. Protoc. 9, 2369-2381. https://doi.org/10.1038/nprot.2014.161.

Tukker, J.J., Lasztóczi, B., Katona, L., Roberts, J.D.B., Pissadaki, E.K., Dalezios, Y., Márton, L., Zhang, L., Klausberger, T., Somogyi, P., 2013. Distinct dendritic arborization and in vivo firing patterns of parvalbumin-expressing basket cells in the hippocampal area CA3. J. Neurosci. 33, 6809-6825. https://doi.org/10.1523/ JNEUROSCI.5052-12.2013.

Uhlrich, D.J., Cucchiaro, J.B., Humphrey, A.L., Sherman, S.M., 1991. Morphology and axonal projection patterns of individual neurons in the cat perigeniculate nucleus. $\mathrm{J}$. Neurophysiol. 65, 1528-1541. https://doi.org/10.1152/jn.1991.65.6.1528.

Unal, G., Crump, M.G., Viney, T.J., Éltes, T., Katona, L., Klausberger, T., Somogyi, Peter, 
2018. Spatio-temporal specialization of GABAergic septo-hippocampal neurons for rhythmic network activity. Brain Struct. Funct. 223, 2409-2432. https://doi.org/10. 1007/s00429-018-1626-0.

Valero, M., Averkin, R.G., Fernandez-Lamo, I., Aguilar, J., Lopez-Pigozzi, D., BrotonsMas, J.R., Cid, E., Tamas, G., Menendez de la Prida, L., 2017. Mechanisms for selective single-cell reactivation during offline sharp-wave ripples and their distortion by fast ripples. Neuron 94, 1234-1247. https://doi.org/10.1016/j.neuron.2017.05. 032. e7.

Valero, M., Cid, E., Averkin, R.G., Aguilar, J., Sanchez-Aguilera, A., Viney, T.J., GomezDominguez, D., Bellistri, E., De La Prida, L.M., 2015. Determinants of different deep and superficial CA1 pyramidal cell dynamics during sharp-wave ripples. Nat. Neurosci. 18, 1281-1290. https://doi.org/10.1038/nn.4074.

Valero, M., English, D.F., 2019. Head-Mounted Approaches for Targeting Single-Cells in Freely Moving Animals. This issue.

Vertes, R.P., Stackman, R.W. (Eds.), 2011. Electrophysiological Recording Techniques, Neuromethods. Humana Press, NY, https://doi.org/10.1007/978-1-60327-202-5.

Viney, T.J., Lasztoczi, B., Katona, L., Crump, M.G., Tukker, J.J., Klausberger, T., Somogyi, P., 2013. Network state-dependent inhibition of identified hippocampal CA3 axoaxonic cells in vivo. Nat. Neurosci. 16, 1802-1811. https://doi.org/10.1038/nn. 3550.

Viney, T.J., Salib, M., Joshi, A., Unal, G., Berry, N., Somogyi, P., 2018. Shared rhythmic subcortical GABAergic input to the entorhinal cortex and presubiculum. Elife 7. https://doi.org/10.7554/eLife.34395.

Wang, Y., Liu, Y.-Z., Wang, S.-Y., Wang, Z., 2016. In vivo whole-cell recording with high success rate in anaesthetized and awake mammalian brains. Mol. Brain 9, 86. https:// doi.org/10.1186/s13041-016-0266-7.

Wertz, A., Trenholm, S., Yonehara, K., Hillier, D., Raics, Z., Leinweber, M., Szalay, G. Ghanem, A., Keller, G., Rózsa, B., Conzelmann, K.-K., Roska, B., 2015. Single-cell-initiated monosynaptic tracing reveals layer-specific cortical network modules. Science 349, 70-74. https://doi.org/10.1126/SCIENCE.AAB1687.

Wheeler, D.W., White, C.M., Rees, C.L., Komendantov, A.O., Hamilton, D.J., Ascoli, G.A., 2015. Hippocampome.org: a knowledge base of neuron types in the rodent hippocampus. Elife 4, 1-28. https://doi.org/10.7554/eLife.09960.

Willadt, S., Canepari, M., Yan, P., Loew, L.M., Vogt, K.E., 2014. Combined optogenetics and voltage sensitive dye imaging at single cell resolution. Front. Cell. Neurosci. 8, 1-8. https://doi.org/10.3389/fncel.2014.00311.

Xu, Y., Zou, P., Cohen, A.E., 2017. Voltage imaging with genetically encoded indicators. Curr. Opin. Chem. Biol. 39, 1-10. https://doi.org/10.1016/j.cbpa.2017.04.005.

Ylinen, A., Bragin, A., Nádasdy, Z., Jandó, G., Szabó, I., Sik, A., Buzsáki, G., 1995. Sharp wave-associated high-frequency oscillation $(200 \mathrm{~Hz})$ in the intact hippocampus: network and intracellular mechanisms. J. Neurosci. 15, 30-46. https://doi.org/10. 1523/JNEUROSCI.15-01-00030.1995. 